\title{
ENERGY ABSORBING EFFECTIVENESS - DIFFERENT APPROACHES
}

\author{
Maria KOTEŁKO*, Mirosław FERDYNUS**, Jacek JANKOWSKI ${ }^{*}$ \\ *Faculty of Mechanical Engineering, Department of Strength of Materials, Lodz University of Technology, \\ 90-924 Łódź, Stefanowskiego 1/15, Poland \\ *Department of Machine Construction and Mechatronics, Lublin University of Technology, \\ 20-618 Lublin, Nadbystrzycka 36, Poland \\ maria.kotelko@p.lodz.pl, m.ferdynus@pollub.pl, jacek.jankowski@p.lodz.pl
}

received 24 May 2017, revised 8 March 2018, accepted 14 March 2018

\begin{abstract}
In the paper the study of different crashworthiness indicators used to evaluate energy absorbing effectiveness of thin-walled energy absorbers is presented. Several different indicators are used to assess an effectiveness of two types of absorbing structures, namely thin-walled prismatic column with flaws and thin-walled prismatic frustum (hollow or foam filled) in both cases subjected to axial compressive impact load. The indicators are calculated for different materials and different geometrical parameters. The problem of selection of the most appropriate and general indicators is discussed.
\end{abstract}

Key words: Thin-Walled Structure, Energy Absorber, Impact, Absorbing Effectiveness

\section{INTRODUCTION}

Since demands of general public of the safe design of components of vehicles, ships, etc. have increased substantially in the last few decades, a new challenge appeared to design special structural members which would dissipate the impact energy in order to limit the deceleration and finally to stop a movable mass (e.g. vehicle) in a controlled manner. Such a structural member termed energy absorber converts totally or partially the kinetic energy into another form of energy. One of the possible design solutions is the conversion of the kinetic energy of impact into the energy of plastic deformation of a thin-walled metallic structural member. There are numerous types of energy absorbers of that kind that are cited in the literature (Alghamdi, 2001). Namely, there are steel drums, thin tubes or multi-corner columns subject to compression, compressed frusta (truncated circular cones), simple struts under compression, sandwich plates or beams (particularly honeycomb cells) and many others. Among all those design solutions, mentioned above, thin-walled metal tubes are widely used as energy absorption systems in automotive industry due to their high energy absorption capability, easy to fabricate, relatively low price and sustainability at collapse. A designer of any impact attenuation device must meet two main, sometimes contrary, requirements: the initial collapse load has to be not too high in order to avoid unacceptably high impact velocities of the vehicle. On the other extreme, the main requirement is a possibly highest energy dissipation capacity, which may not be achieved if the collapse load of the impact device is too low. The latter may result in dangerously high occupant "ride down" decelerations.

Thus, maximizing energy absorption and minimizing peak to mean force ratio by seeking for the optimal design of these components are of great significance. There are several crashworthiness indicators (Jones, 2003; Kotełko, 2010) used to evaluate the crashworthiness of the energy absorbing structure (energy absorber): energy absorption (EA), peak crushing force (PCF), mean crushing force (MCF), crash load efficiency (CLE), stroke efficiency (STe). These indicators allow one to compare energy absorption capability within one particular material and one structural geometry (design solution). Thus, an alternative energy absorbing effectiveness factor was introduced recently by Jones (2010), which is supposed to enable a selection of most proper material and design solution of an energy absorbing structure.

\section{ENERGY ABSORBING EFFECTIVENESS INDICATORS - OVERVIEW}

As mentioned above, there are several crashworthiness indicators used to evaluate the crashworthiness of the energy absorbing structure (energy absorber). The typical crushing force displacement curve for a thin-walled member subjected to axial impact is shown in Fig.1.

$$
E A\left(d_{x}\right)=\int_{0}^{d_{x}} F(x) d x
$$

where $d_{x}$ is a crushing distance (see Fig.1).

The factor, which directly indicates absorbing effectiveness is the energy absorbed (EA) given by relation (1), or specific energy (energy per unit mass) $S_{e}$, given by (2), where $m$ is a mass of the absorber.

$S_{e}=\frac{E A}{m}$

Since the reduction of an initial peak crushing force (PCF) is mostly desirable from biomechanical reasons, this factor is an important indicator of the absorber effectiveness.

The mean crushing force (MCF - Fig.1.) for a given crushing deformation $d_{x}$ is calculated as: 


$$
M C F=\frac{E A\left(d_{x}\right)}{d_{x}}
$$

Crash load efficiency is defined as a mean crushing force (MCF) to peak crushing force (PCF - see Fig.1) ratio:

$$
C L E=\frac{M C F}{P C F} \cdot 100 \%
$$

The CLE factor should be as close to $100 \%$ as possible in practice and CLE of an ideal energy absorber is $100 \%$.

Another crashworthiness indicator is the stroke efficiency, which represents the deformation capacity of an absorber. Stroke efficiency $\mathrm{St}_{\mathrm{e}}$ is defined as follows:

$$
S t_{e}=\frac{L_{o}-U}{L_{o}} \text {. }
$$

where: $L_{o}$ - initial length (characteristic dimension) of the member [mm], $U$ - maximum shortening (maximum characteristic deformation) of the member. The most desirable is the lowest value of this factor, corresponding to the highest value of the crushing distance.

A combination of the CLE and the stroke efficiency was defined by Hanssen et al. (2000) as total efficiency TE to assess the whole performance of an energy absorber. It is a dimensionless number and is given by

$$
T E=C L E \times S t_{e}
$$

However, this total efficiency does not include the factor of the weight of the structures and therefore another index was introduced by Zhang et al. (2009), who proposed to divide the total efficiency by the mass. This factor is defined it as specific total efficiency and expressed as follows:

$$
S T E=\frac{T E}{m}=\frac{C L E \times S t_{e}}{m}
$$

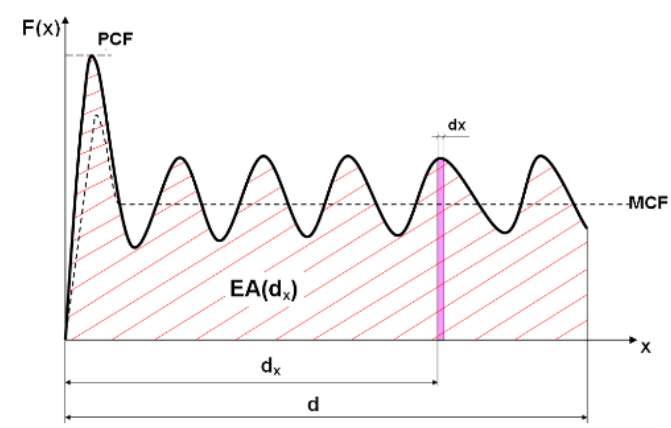

Fig. 1. Exemplary load-shortening diagram of thin-walled column under axial impact

All indicators, mentioned above express an absorber characteristics within one specific structural geometry and one absorber's material. The first indicator, which included the material factor was introduced by Pugsley and Jones (2003), termed structural efficiency and defined as:

$\eta=\frac{M C F}{A \cdot \sigma_{0}}$

where: $\sigma_{0}$ - yield stress, $A$ - area of the absorber cross-section.

Any comparisons between the characteristics of energy absorbers, made from different materials are difficult using indicators, mentioned above , to some extent except structural efficiency given by (8). Thus, a new alternative approach to the assessment of energy absorbing effectiveness has been proposed by Jones (2010). He proposed the factor defined as:

$$
\Psi_{0}=\frac{\text { total elastic and plastic energy absorbe } d \text { by a absorber }}{\text { energy absorbed in the same volume of material specimen up to failure in tension }}
$$

In the case of axial crushing, Jones derived an approximate relation determining this factor as follows (Jones, 2010):

$\Psi_{0}=\frac{3 m v^{2}}{8 \sigma_{0} A \delta_{f} \varepsilon_{R}}$

where: $m$ - mass of impactor, $v$ - initial impact velocity, $\sigma_{0}$ - yield stress, $A$ - area of the absorber cross-section, $\delta_{f}$ - final axial displacement (shortening), $\varepsilon_{R}$ - rupture strain.

In the case of foam filled structure, the denominator in (9) incorporates energy of the same volume of foam material tensile test specimen, as follows:

$\Psi_{0}=\frac{3 m v^{2}}{8 \delta_{f} \varepsilon_{R}\left(\sigma_{0} A_{s}+\sigma_{f} A_{f}\right)}$

where: $\sigma_{f}$ - yield stress of the foam material, $A_{s}$ - area of the shell (face sheet), $A_{f}$ - area of the foam.

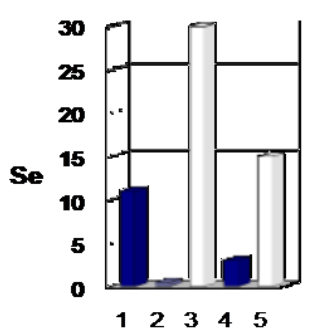

Fig. 2. Specific energies (Se ) for selected energy absorbers (1 - top hat, 2 - plain channel, 3 - crushing tube, 4 - hydraulic device, 5 - aluminum honeycomb)

A direct measure of the absorber's effectiveness, energy absorbed during crushing process, can be compared within one type of absorber's structure, material, etc. A comparison of specific energy absorbed by different types of absorbers is shown in Fig. 2. As shown, the most effective is a circular thin-walled tube. Thus, since early 60ties of XXth Century, the majority of the studies were devoted to this type of energy absorber, made of mild steel (Jones, 2003). However, in more recent years, investigators have examined prismatic tubes of various cross-sectional shapes, made of different materials (high strength steel, aluminum, etc.), also filled with different foam materials.

Another alternative solution are flaws or dents acting as triggers. A trigger may induce the most desirable crushing (collapse) mode, leading to higher energy absorption and mean to peak crushing force ratio. Very few published papers deal with tubular structures with dents or other flaws (Ferdynus et al., 2016, 2018). An interesting solution has been presented by Yang (2017). The subject of investigation was the crushing behavior of a thinwalled circular tube with internal gradient grooves. The authors fabricated stainless steel thin-walled tube with preset internal circumferential rectangular groove defects using SLM 3D printing method. They observed double buckling-splitting crushing mode. Empty and foam-filled circumferentially grooved thick-walled circular tubes under axial low velocity impact were investigated theoretically and experimentally by Darvizeh et al. (2017).

A different concept of energy absorbing structures represent compressed thin-walled frusta (truncated circular cones or prisms) (Alghamandi, 2001; Mołdawa and Kotełko, 2016), currently used as impact attenuation members in car structures, mainly due to the reduction of the peak crushing load in relation to parallelepi- 
ped. There are relatively few published results, concerning this type of energy absorbing members (Fredynus et al., 2016; Mołdawa and Kotełko, 2016). Ei-Sobky et al. (2001) investigated crushing behavior of conical truncated frusta. They analyzed influence of boundary conditions on the peak and mean crushing load. Very recently, Sarkabiri et al. (2015) published the results of multiobjective crashworthiness optimization of thin-walled conical groove tubes filled with polyurethane foam. They stated, that the conical angle reduces the peak crushing force, however it reduces also the absorbed energy.

\section{SUBJECTS OF THE COMPARATIVE STUDY}

The aim of the present study was a comparative analysis of energy absorption capability of selected thin-walled energy absorbers (prismatic columns under axial impact) expressed by selected crash-worthiness indicators. Subjects of the analysis were prismatic thin-walled tubes with flaws (Fredynus et al., 2016, 2018) and prismatic, hollow and foam filled thin-walled frusta (Fredynus et al., 2016; Mołdawa and Kotełko, 2016), shown in (Fig. 2). a)

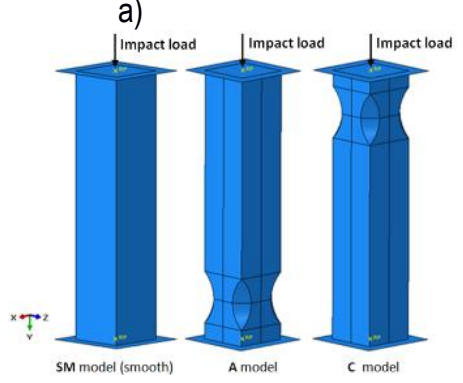

b)

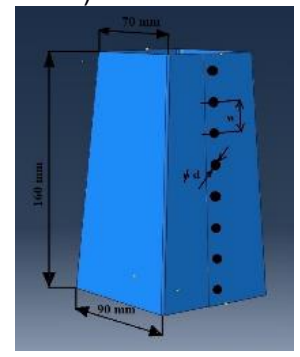

Fig. 3. Energy absorbing structures: a) - prismatic thin-walled tube with flaws (dents) (Jones, 2010), b) - prismatic thin-walled frustum (Fredynus et al., 2016; Mołdawa and Kotełko, 2016)

In the first case (Fig. 3a), the subject of investigation was a thin-walled square section aluminum tube with four indentations in the corners. The tubes of dimensions $70 \times 2$ and height $\mathrm{l}=335 \mathrm{~mm}$ were investigated. The dents geometry was characterized by the main radius $R=50 \mathrm{~mm}$ and relative dent depth with respect to the dimension b of main diagonal (Fig. 3) of the column cross-section (from $5 \%$ up to $30 \%$ ). Dents were made at the bottom of the column or at the top. The models with the dents at the bottom of the column were designated by the symbols from A05_X to A30_X, where the first number stands for the relative depth of the dent (in percent) and $X$ stands for the distance of the dent from the bottom (Fig. 4). The column with smooth walls (without dents) was designated as SM. In the second case (Fig. 3b), the subject of investigation was a thin-walled prismatic frustum on square foundation of constant edge length $a=90 \mathrm{~mm}$ and height $h=160$ $\mathrm{mm}$, hollow or foam-filled.

\section{CRASHWORTHINESS COMPARATIVE ANALYSIS}

The comparative analysis was focused on the following indicators: peak crushing force (PCF), mean crushing force (MCF), crash load efficiency (CLE), stroke efficiency (Ste) and alternative energy absorbing effectiveness factor $\psi_{0}$.

\subsection{PCF and CLE}

The comparison of decrease of PCF in examined absorbers is shown in Fig. 4 and 5. Fig. 4 shows load-shortening diagrams for flawed prismatic columns. The maximum decrease in PCF amounts about $25 \%$. Fig. 5 shows corresponding diagrams for hollow frusta of different frustum angle. The decrease of PCF is more significant and amounts up to $50 \%$. Diagrams of CLE for absorbers under investigation are shown in Fig. 6 and 7 Also this indicator reaches higher values for hollow frusta. CLE indicator does not differ significantly for different materials. The maximum for steel flawed column is about $36 \%$, while for aluminium column - 39\%. Maximum CLE for both steel and aluminium hollow frustum is about $70 \%$. The decrease of PCF and increase of CLE are main advantages of both examined absorbers.

Foam filling of frusta for examined materials (steel and aluminum) did not affect either PCF or CLE (Fig. 14).
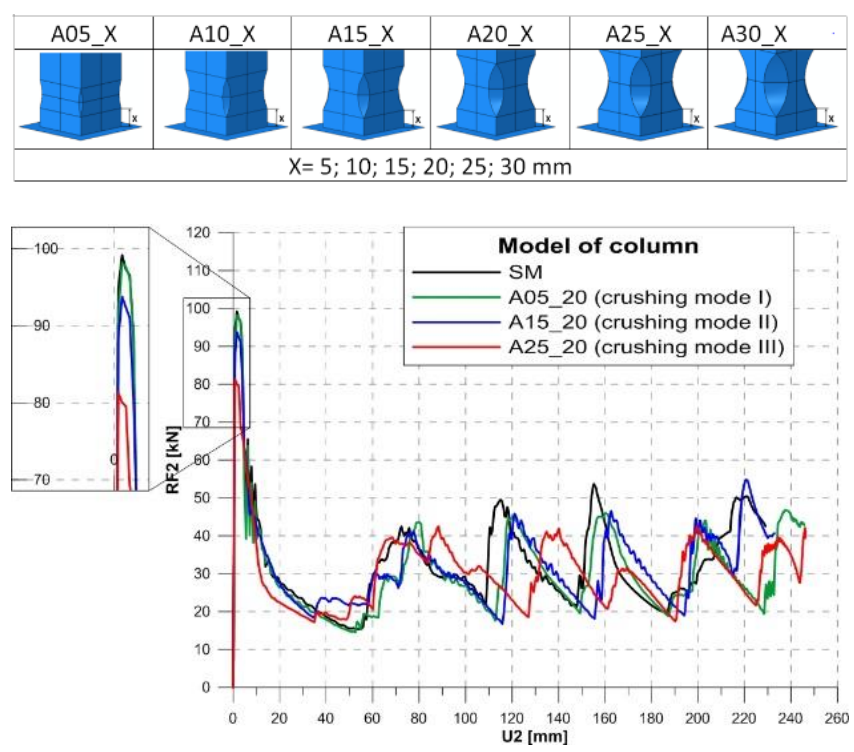

Fig. 4. Load-shortening diagrams for columns $A$ exhibiting three different crushing modes (constant value of $X=20 \mathrm{~mm}$ ); $v_{0}=10 \mathrm{~m} / \mathrm{s}$, impactor mass $m=200 \mathrm{~kg}$ (Ferdynus et al., 2016)

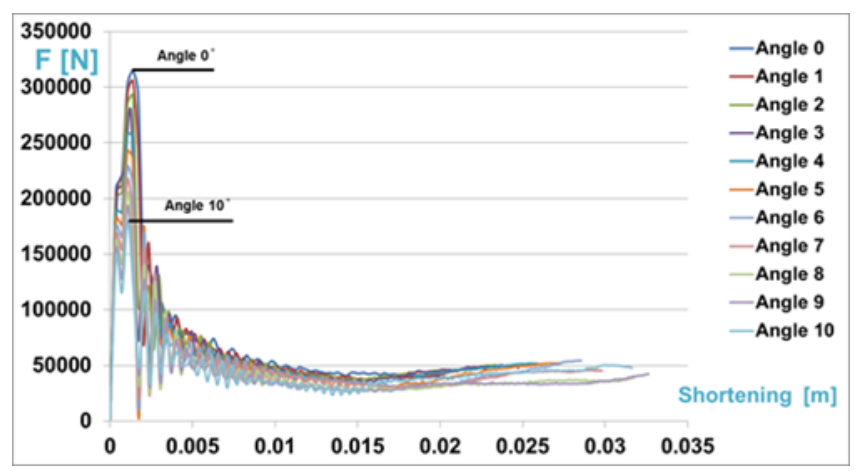

Fig. 5. Load shortening diagrams for hollow thin-walled frustum of different frustum angle; $=0.8 \mathrm{~mm}, \mathrm{v}_{0}=6.2 \mathrm{~m} / \mathrm{s}$, impactor mass $\mathrm{m}=50 \mathrm{~kg}$ (Mołdawa and Kotełko, 2016). 


\section{CLE [\%]}

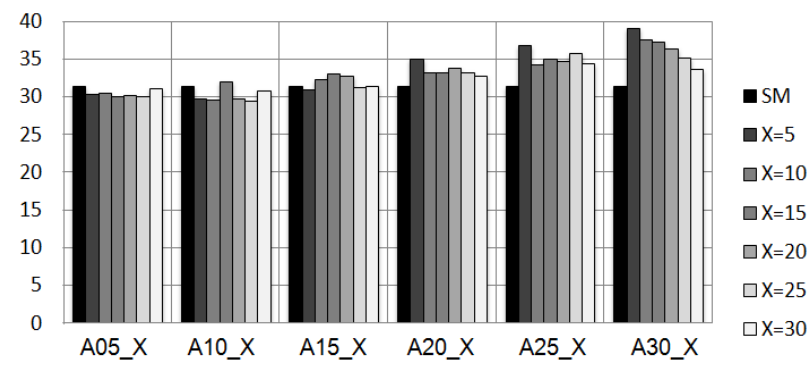

Fig. 6. Flawed prismatic thin-walled steel columns: crash load efficiency (CLE) $v_{0}=10 \mathrm{~m} / \mathrm{s}$, impactor mass $\mathrm{m}=200 \mathrm{~kg}$ (Ferdynus et al., 2018)

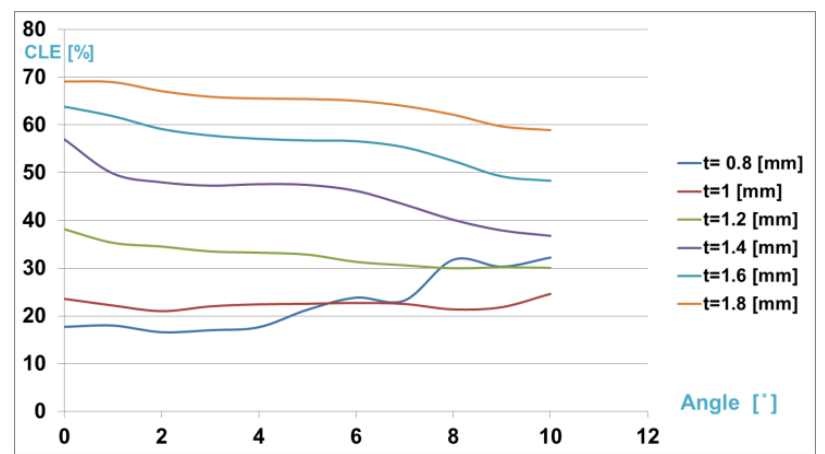

Fig. 7. Steel hollow frustum: Crash load efficiency $(C L E) ; v_{0}=6.2 \mathrm{~m} / \mathrm{s}$, impactor mass $\mathrm{m}=50 \mathrm{~kg}$ (Mołdawa and Kotełko, 2016)

\subsection{Stroke efficiency}

Comparison of the stroke efficiency (measure of deformation capacity) for two types of absorbers under investigation give diagrams in Figs. 8 and 9.

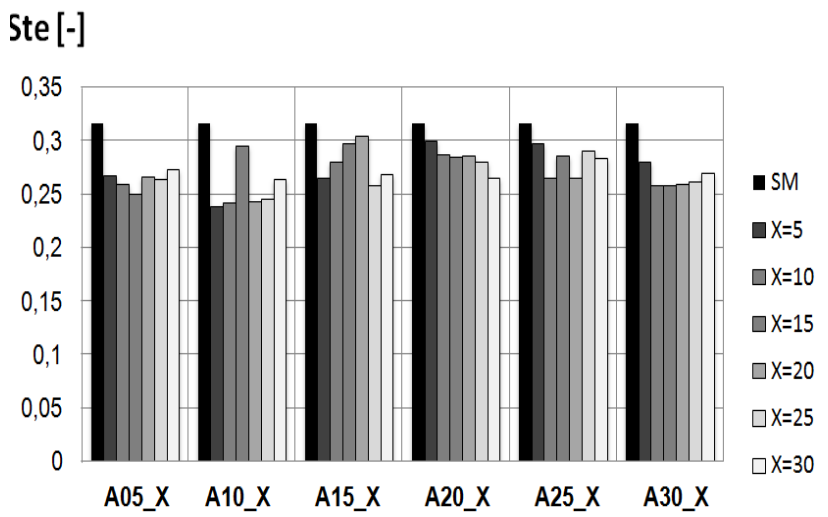

Fig. 8. Flawed prismatic thin-walled steel columns: stroke efficiency (Ste), v0 $=10 \mathrm{~m} / \mathrm{s}$, impactor mass $\mathrm{m}=200 \mathrm{~kg}$ (Ferdynus et al., 2018)

In the contrary to CLE the stroke efficiency is lower (more optimal) for flawed columns in comparison with hollow frusta. It also depends much more significantly on the absorber's material. It is related not only to the material stiffness, but also to differences in failure modes (see Fig. 11 and 12). Fig. 11 and 12 (loadshortening diagrams) show the difference in structural behaviour of examined absorbers made of steel and aluminium. In the case of hollow frusta stroke efficiency is less sensitive to the material.

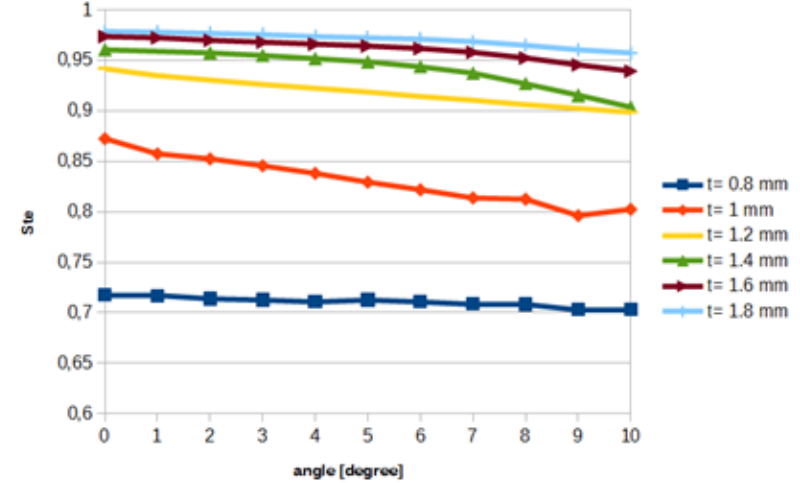

Fig. 9. Steel hollow frustum: stroke efficiency (Ste); $0=6.2 \mathrm{~m} / \mathrm{s}$, impactor mass $\mathrm{m}=50 \mathrm{~kg}$ (Mołdawa and Kotełko, 2016)

Stroke efficiency for foam filled frustum, because of increased structural stiffness, is higher in comparison with hollow frustum (Fig.14).

Fig. 10 shows maps of crash load efficiency (CLE) (Fig.10a) and stroke efficiency (Ste) (Fig. 10b) for flawed columns with different relative dent depth and dent position [8], obtained from FE simulations. As it is presented, optimal values of these two indicators (the highest CLE and lowest Ste) are obtained for different magnitudes of dent depth and position. Thus, using different effectiveness factors in optimization procedure, we may obtain different solutions.

a)

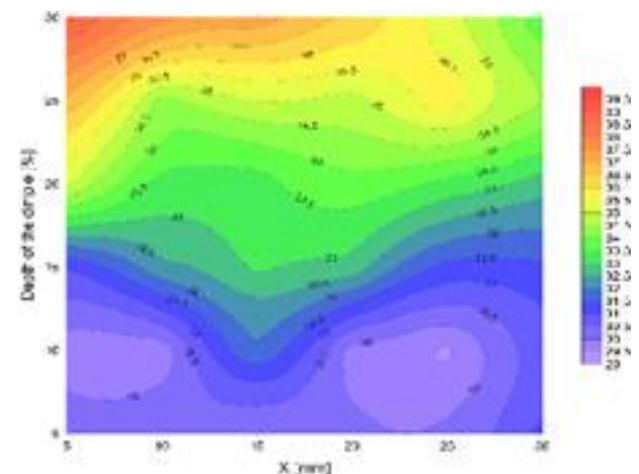

b)

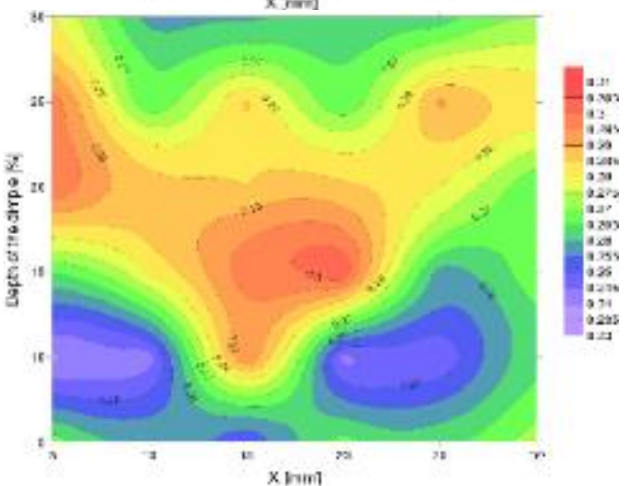

Fig. 10. Two crashworthiness indicators for flawed prismatic aluminium thin-walled columns: a) crash load efficiency (CLE),

b) stroke efficiency (Ste) (Ferdynus et al., 2018)

Tables 1 and 2 show, that all crashworthiness indicators mentioned above, particularly CLE and Ste, depend on an impact energy and, on the other extreme (at constant impact energy) on the initial impact velocity. It also induces the question about an adequate effectiveness measure to be still open. 


\subsection{Energy absorbing effectiveness factor - alternative approach}

An alternative energy absorbing effectiveness factor was introduced by Jones (2010), in order to enable a selection of most proper material and design solution of an energy absorbing structure. Its main advantage is a possibility of comparing energy effectiveness not only within one structural design solution, but among different types of energy absorbing structures as well. As shown in Tabs. 1 and 2, this effectiveness factor does not depend significantly on an impact energy or initial velocity, which makes this effectiveness measure more general.

Tab. 3 contains values of effectiveness factor $\psi_{0}$ for considered two types of energy absorbing structures.

Tab. 1. Crashworthiness indicators for flawed prismatic steel columns, at constant initial impact velocity $v_{0}=10 \mathrm{~m} / \mathrm{s}$

\begin{tabular}{|c|c|c|c|c|c|c|}
\hline $\begin{array}{c}\text { impact } \\
\text { energy } \\
{[\mathrm{kJ}]}\end{array}$ & $\begin{array}{c}\text { Mass } \\
\mathrm{m}[\mathrm{kg}]\end{array}$ & PCF & $\begin{array}{c}\text { MCF } \\
{[\mathrm{kN}]}\end{array}$ & $\begin{array}{c}\mathrm{CLE} \\
{[\%]}\end{array}$ & Ste & $\boldsymbol{\Psi}_{0}$ \\
\hline 7.5 & 150 & 171.895 & 53.283 & 30.997 & 0.580 & 3.60 \\
\hline 10 & 200 & 172.105 & 49.611 & 28.826 & 0.399 & 3.63 \\
\hline 15 & 300 & 172.286 & 56.006 & 32.508 & 0.200 & 3.78 \\
\hline 20 & 400 & 172.379 & 69.057 & 40.061 & 0.135 & 4.66 \\
\hline
\end{tabular}

Tab. 2. Crashworthiness indicators for flawed prismatic steel columns, at constant impact energy $E A=14 \mathrm{~kJ}$

\begin{tabular}{|c|c|c|c|c|c|c|}
\hline $\begin{array}{c}\mathbf{V} \\
{[\mathrm{m} / \mathbf{s}]}\end{array}$ & $\begin{array}{c}\text { Mass } \\
{[\mathrm{kg}]}\end{array}$ & $\begin{array}{c}\text { PCF } \\
{[\mathrm{kN}]}\end{array}$ & $\begin{array}{c}\text { MCF } \\
{[\mathrm{kN}]}\end{array}$ & $\begin{array}{c}\text { CLE } \\
{[\%]}\end{array}$ & $\begin{array}{c}\text { Ste } \\
{[\%]}\end{array}$ & $\boldsymbol{\Psi}_{0}$ \\
\hline 2 & 7000 & 138.433 & 49.085 & 35.458 & 0.150 & 3.32 \\
\hline 4 & 1750 & 150.381 & 49.835 & 33.139 & 0.162 & 3.36 \\
\hline 6 & 777.78 & 158.747 & 51.122 & 32.203 & 0.183 & 3.46 \\
\hline 8 & 437.50 & 168.787 & 52.270 & 30.968 & 0.207 & 3.56 \\
\hline 10 & 280 & 189.54 & 54.249 & 28.622 & 0.228 & 3.64 \\
\hline
\end{tabular}

Tab. 3. Energy absorbing effectiveness factor $\psi_{0}$

\begin{tabular}{|c|c|c|c|}
\hline Type of absorber & $\begin{array}{c}\text { Material/ } \\
\text { Yield stress } \\
{[\mathrm{MPa}]}\end{array}$ & $\begin{array}{c}\text { Mass of } \\
\text { impactor }[\mathrm{kg}] / \\
\text { Initial velocity } \\
{[\mathrm{m} / \mathbf{s}]}\end{array}$ & $\boldsymbol{\Psi}_{0}$ \\
\hline $\begin{array}{c}\text { Hollow parallelpiped } \\
\mathrm{\alpha}=0^{\circ}\end{array}$ & Steel $/ 590$ & $50 / 6$ & 0.78 \\
\hline $\begin{array}{c}\text { Hollow frustum } \\
\mathrm{a}=2^{\circ}\end{array}$ & Steel/590 & $50 / 6.2$ & 0.76 \\
\hline $\begin{array}{c}\text { Hollow frustum } \\
\mathrm{a}=5^{\circ}\end{array}$ & Steel/590 & $50 / 6.2$ & 0.76 \\
\hline $\begin{array}{c}\text { Hollow frustum } \\
\mathrm{a}=10^{\circ}\end{array}$ & Steel/590 & $50 / 6.2$ & 0.72 \\
\hline $\begin{array}{c}\text { Hollow frustum } \\
\mathrm{a}=10^{\circ}\end{array}$ & Aluminium/175 & $50 / 6.2$ & 2.79 \\
\hline $\begin{array}{c}\text { Foam filled frustum } \\
\mathrm{a}=5^{\circ}\end{array}$ & $\begin{array}{c}\text { Steel/590 } \\
\text { Polypropylene/- }\end{array}$ & $50 / 6.2$ & 1.36 \\
\hline Smooth column & Aluminium/175 & $200 / 10$ & 2.77 \\
\hline $\begin{array}{c}\text { Flawed column } \\
\text { A30_5 }\end{array}$ & Aluminium/175 & $200 / 10$ & 2.64 \\
\hline $\begin{array}{c}\text { Flawed column } \\
\text { A30_5 }\end{array}$ & Steel/165 & $200 / 10$ & 3.72 \\
\hline
\end{tabular}

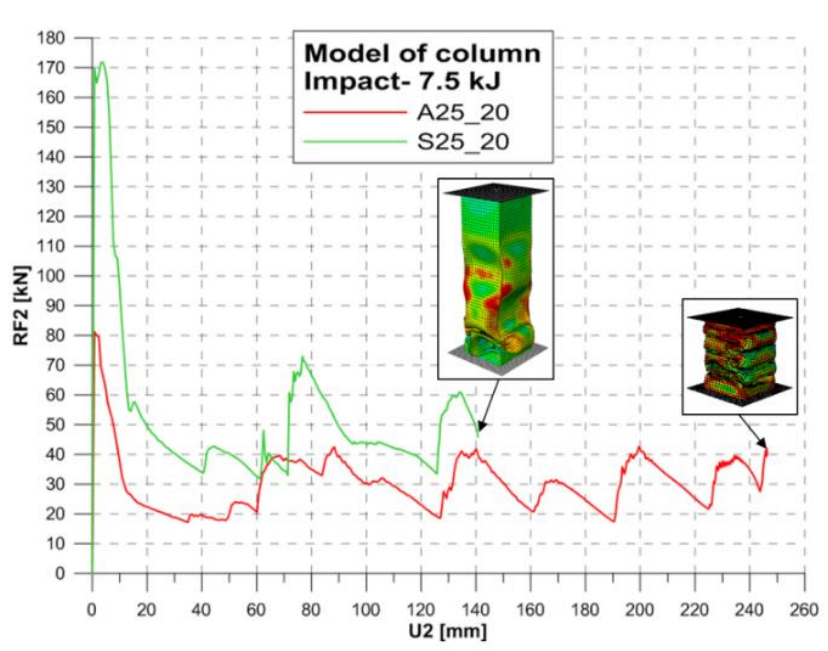

Fig. 11. Load-shortening diagrams of flawed prismatic thin-walled steel and aluminium columns; $v 0=10 \mathrm{~m} / \mathrm{s}$, impactor mass $m=200 \mathrm{k}$

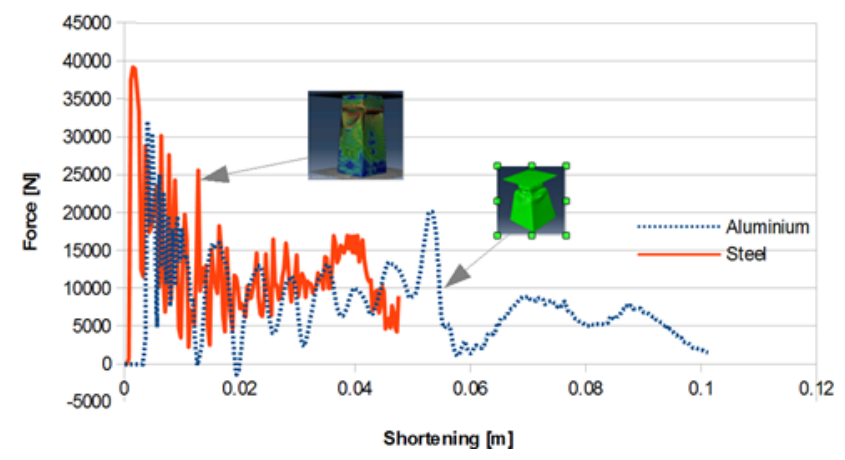

Fig. 12. Load-shortening diagrams of thin-walled steel and aluminium frusta; $v 0=6.2 \mathrm{~m} / \mathrm{s}$, impactor mass $\mathrm{m}=50 \mathrm{~kg}$

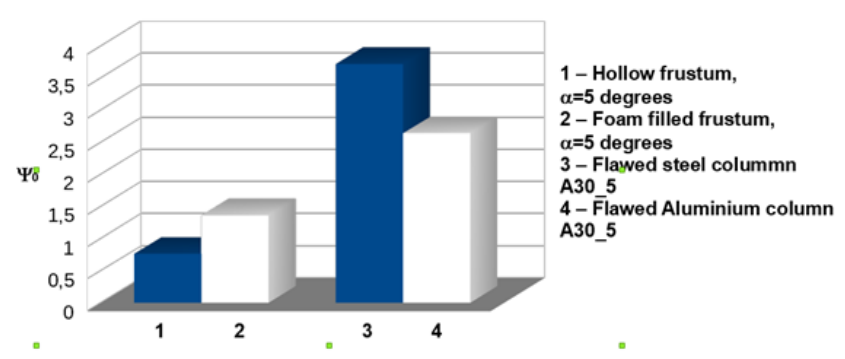

Fig.13. Energy absorbing effectiveness factor $\Psi_{0}$ for two examined types of absorbers - comparison

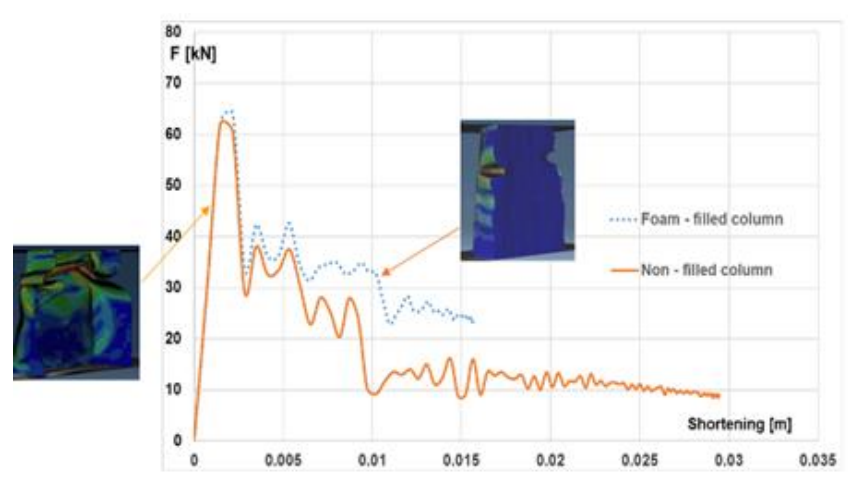

Fig. 14. Load-shortening diagrams for thin-walled hollow and foam filled frustum; steel metal sheet, polypropylene filling; $v 0=6.2 \mathrm{~m} / \mathrm{s}$, impactor mass $m=50 \mathrm{~kg}$ 


\section{FINAL REMARKS}

Higher values of energy absorbing effectiveness factor $\psi_{0}$ have been obtained for flawed tubes (Fig.1a) in comparison with thin-walled frusta (Fig.1b). However, within one type of absorbing structure this factor does not indicate the best solution. For example, PCF or CLE indicators, very important from biomechanical point of view, are higher for flawed column than for smooth column (Fig. 1a) and higher for frustum, than for parallelepiped (Fig. 1b), in the contrary to the effectiveness factor $\psi_{0}$ (Tab. 3). Thus, it may be concluded, that the energy absorbing effectiveness factor $\psi_{0}$ may be used in a preliminary analysis, leading to a selection of an absorber's type. After this initial selection, within one type of absorbing structure, other crashworthiness indicators, particularly important for specific absorber's purposes, should be taken into account. However, appropriate general indicator (or indicators) of energy absorption capability is still an open question and demands further comparative analysis.

\section{REFERENCES}

1. Alghamdi A.A.A. (2001), Collapsible impact energy absorbers: an overview, Thin-Walled Struct, 39, 189-213.

2. Darvizeh A., Meshkinzar A., Alitavol M., Rajabierhard R. (2017), Low velocity impact of empty and foam filled circumferentially grooved thick-walled circular tubes, Thin-Walled Struct., 110, 97-105.

3. Ei-Sobky H., Singace A.A., Petsios R. . (2001), Mode of collapse and energy absorption characteristics of constrained frusta under axial impact loading. Int.J.Mech.Sci., 43, 743-757.

4. Ferdynus M., Kotełko M.,Kral J. (2018) Energy absorption capability numerical analysis of thin-walled prismatic tubes with corner dents under axial impact, accepted for publication, Maintenance and Reliability, v.20 (2), 248-255

5. Ferdynus M., Kotełko M., Mołdawa A. (2016), Prismatic tubular thin-walled members as energy absorbers, chapter in Statics, dynamics and stability of structures, (series of monographs) ed. by R.J. Mania, Lodz University of Technology, 4, 178-195.

6. Hanssen A.C., Langseth M., Hopperstad O.S. (2000), Static and dynamic crushing of circular aluminium extrusions with aluminium foam filler, International Journal of Impact Engineering, 24(5), 475-507.

7. Jones N. (2003), Structural Impact, Cambridge University Press.

8. Jones N. (2010), Energy absorbing effectiveness factor, Int. J. of Impact Engineering, 37, 754-765.

9. Kotełko M. (2010), Load-capacity and mechanisms of failure of thinwalled structures (in Polish), WNT, Warszawa.

10. Mołdawa A., Kotełko M. (2016), Impact behaviour of spot-welded thin-walled frusta, Acta Mechanica et Automatica, 10 (4), 280-284

11. Sarkabiri B., Jahan A., Rezvani M. (2015), Multi-objective crashworthiness optimization of thin-walled conical groove tubes filled with polyurethane foam, 3 rd Polish Congress of Mechanics, 21 st International Conference of Computer Methods in Mechanics, 947-948.

12. Zhang X., Cheng G., Zhang H. (2009), Numerical investigations on a new type of energy-absorbing structure based on free inversion of tubes, Int. J. of Mechanical Sciences, 51, 64-76.

13. Zhe Y., You Y., Wei Y., Huang Ch. (2017), Crushing behaviour of a thin-walled circular tube with internal gradient grooves fabricated by SLM 3D printing, Thin-Walled Struct., 111, 1-8. 